

\section{SOBRE OS AUTORES}

Giancarlo Philippi Zacchi | gianpzacchi@gmail.com | Lattes: http://lattes.cnpq.br/4715321123853254

Doutorando no Programa de Pós-Graduação em Design na Universidade Federal de Santa Catarina. Pesquisador do Núcleo de Gestão de Design e do Laboratório de Usabilidade, (NGD/LDU - UFSC). Colabora na geração de conhecimento nas áreas de agricultura familiar em taxonomias e turismo, por meio da valorização, identificação e proteção, bem como desenvolvimento regional e sustentável. Mestrado em Administração pelo Centro de Pós-Graduação em Administração da Universidade Federal de Santa Catarina, Especialização em Perícia, Auditoria e Gestão Ambiental. Graduação em Turismo. Participa de projetos junto a pequenos produtores rurais. Professor de graduação e pós-graduação.

Eugenio Andrés Díaz Merino | eugenio.merino@ufsc.br | Lattes: http://lattes.cnpq.br/9181118757331104

Possui graduação em Desenho Industrial pela Universidade Federal do Rio de Janeiro, mestrado em Engenharia de Produção pela Universidade Federal de Santa Catarina e doutorado em Engenharia de Produção pela Universidade Federal de Santa Catarina. Atualmente é professor Titular da Universidade Federal de Santa Catarina e coordena o Núcleo de Gestão de Design e o Laboratório de Design e Usabilidade. Tem experiência na área de Design e Engenharia. Participa dos programas de pós-graduação em Design e Engenharia de Produção ambos da UFSC. É pesquisador CNPq (PQ1C), Coordenador do Comité Assessor do CNPq (CA DI) e líder do grupo de pesquisa em Gestão de Design.

Giselle Schmidt Alves Díaz Merino | gisellemerino@gmail.com | Lattes: http://lattes.cnpq.br/4622661220646221

Pesquisadora e Professora permanente do Programa de Pós-graduação em Design da Universidade Federal de Catarina e do Programa de Pós-Graduação em Design da UNIVILLE. Realizou pós-doutorado no Programa de Pós-graduação em Design da Universidade do Estado de Santa Catarina. Doutora em Engenharia de Produção, com ênfase em Engenharia de Produto e Processo linha de pesquisa metodologias de projeto de Design pela Universidade Federal de Santa Catarina. Mestre em Design pelo Programa de Pós-Graduação em Design pela Universidade Federal de Santa Catarina. Possui formação em Processos Grupais e Coordenação de Equipes. Coordenadora de Projetos do Núcleo de Gestão de Design e do Laboratório de Design e Usabilidade da Universidade Federal de Santa Catarina desde o ano de 2000. Ministra disciplinas de Metodologia de Desenvolvimento de Projeto; Design Centrado no Usuário; Ergonomia e Usabilidade em Produtos e Serviços, dentre outras, bem como orientação e coorientação de alunos de graduação e pós-graduação, projetos de pesquisa e extensão. Atua em projetos de Design junto a Agricultura Familiar desde o ano 2000 e projetos de Design na área da Saúde. Membro da Rede de Pesquisa e Desenvolvimento em Tecnologia Assistiva (RPDTA). Possui como foco de pesquisa: Gestão de Design, Design Centrado no Usuário, Design Universal/Inclusivo em Produtos e Serviços.

Adriana Tomazi Alves | adritomazi@epagri.sc.gov.br | adritomazi@epagri.sc.gov.br

Possui graduação em Agronomia pela Universidade Federal de Santa Catarina. Atua há 15 anos na Empresa de Pesquisa Agropecuária e Extensão Rural de Santa Catarina - Epagri. Na empresa exerceu a função de extensionista rural em três municípios: Celso Ramos, Corupá e Jaraguá do Sul e de líder do Programa Gestão de Negócios e Mercado em duas regiões: Joinville e Florianópolis. Atualmente responde pela gerência regional de Florianópolis, com área de abrangência em 20 municípios, sendo também responsável na Epagri pelo projeto Valorização e Identificação de Empreendimentos Rurais e Pesqueiros, com base na Competitividade, Diferenciação e Sustentabilidade, nas regiões de Joinville, Blumenau e Florianópolis.

\section{Dione Nery Cavalcanti Benevenutti | dionenery@epagri.sc.gov.br}

Possui graduação em Agronomia e Mestrado em Administração Rural e Comunicação Rural pela Universidade Federal Rural de Pernambuco. Pós-graduação em Engenharia de Segurança do Trabalho pela Unisociesc - Joinville. Atua há 13 anos na Empresa de Pesquisa Agropecuária e Extensão Rural de Santa Catarina - Epagri. Na empresa exerceu a função de extensionista rural no município de Garuva de 2006 a 2015. Atualmente exerce a função de extensionista rural no município de Joinville e de líder do Programa Gestão de Negócios e Mercado na região de Joinville, Blumenau e Itajaí. Participa como membro da equipe do projeto Valorização e Identificação de Empreendimentos Rurais e Pesqueiros, com base na Competitividade, Diferenciação e Sustentabilidade, com atuação nas regiões de Joinville e Blumenau. 


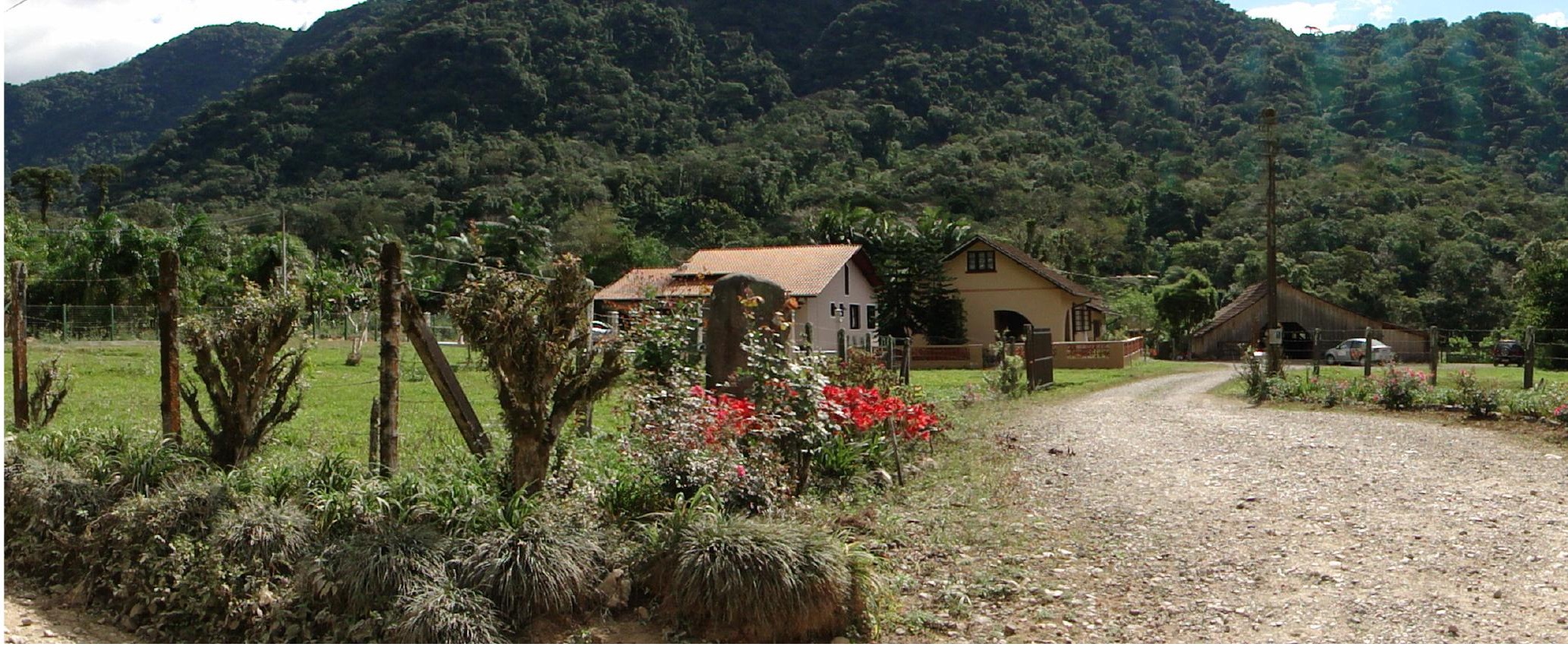

\title{
Relato da experiência de valorização da agricultura familiar no norte do estado de Santa Catarina, por meio da gestão de design
}

\author{
Experience report of promoting family farming \\ in the north of Santa Catarina state through \\ the design management
}

Giselle Schmidt Alves Díaz Merino, Giancarlo Philippi Zacchi, Adriana Tomazi Alves, Dione Nery Cavalcantid Benevenutti, Eugenio Andrés Díaz Merino

\section{Resumo}

A agricultura familiar destaca-se no cenário econômico e na produção de alimentos. Contudo mesmo diante de políticas de apoio à atividade, enfrenta desafios como a baixa geração e distribuição de ocupação e renda; êxodo e perda da diversidade. A gestão de design pode identificar potencialidades e oportunidades de melhoria e propor ações, para valorização da agricultura familiar. 0 objetivo deste artigo é relatar a experiência de valorização da agricultura familiar no norte de Santa Catarina. O estudo é descritivo, de natureza aplicada, abordagem qualitativa, com levantamento bibliográfico e documental em estudo multicaso aplicado em Blumenau e Joinville. Observou-se que as propriedades apresentam uma produção diversificada, muito embora haja especialização; Que $84,62 \%$ dos empreendimentos demonstram interesse em explorar o turismo organizado e que a abordagem do design nos casos estudados, pode orientar a valorização da agricultura e estimular o desenvolvimento local.

Palavras-chave: Gestão de design; Valorização; Agricultura Familiar.

\begin{abstract}
Family farming has gained more evidence in the economic scenario as well as in the food production. However, regarding the public policies supporting this activity, it still faces challenges such as low generation and distribution of employment and income; exodus and the loss of agriculture diversity. The design management may identify areas of potential, the improvement opportunities as well as propose actions by adding value to the family farming. The objective of this article is to report the experience of valuing family farming in the north of Santa Catarina. This article is descriptive, as applied nature, qualitative approach, with a documental and bibliographic procedure based on a multi-case study applied in Blumenau and Joinville. It has been established that the properties show a diversified production, although there is specialization; which $84.62 \%$ of the ventures show interest in exploring the organized tourism and, the design approach in the study cases may guide the agriculture development and also enhance the performance of local development.
\end{abstract}

Keywords: Design management; Valorization; Family farming. 


\section{INTRODUÇÃO}

O Conselho Nacional de Desenvolvimento Rural Sustentável - CONDRAF, (2017), órgão integrante do Ministério do Desenvolvimento Agrário, afirma que o espaço rural brasileiro foi marcado via de regra pelo controle econômico das oligarquias tradicionais. Este domínio trouxe para o espaço rural destruição dos recursos naturais; elevado grau de desigualdades sociais; fome; pobreza; exclusão social e redução do dinamismo econômico.

Contudo destaca-se que com o avanço das políticas públicas atingindo cada vez mais o rural brasileiro, a agricultura familiar tem conseguido mais segurança e respeito, cumprindo seu papel na superação da fome e da miséria no Brasil, tendo o Plano Safra para Agricultura Familiar 20162017, reafirmado o compromisso de ampliar a produção de alimentos seguros (MDA, 2017).

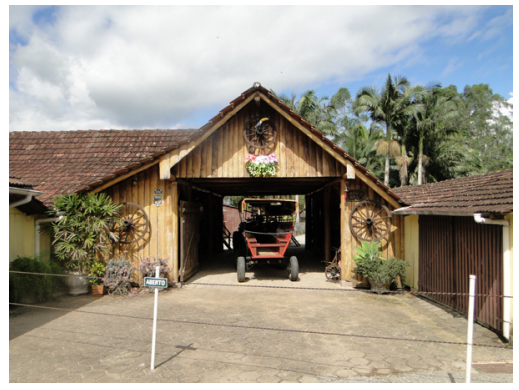

Figura 1: Fachada propriedade rural Estrada Bonita - Joinville - SC. Fonte: Acervo NGD, 2016.
A aprovação da agenda 2030 para o desenvolvimento sustentável pela Assembleia Geral das Nações Unidas em setembro de 2015, oferece uma visão de mundo mais justa, pacífica e sustentável, e propõe no âmbito das relações internacionais, ações que fortaleçam os objetivos sustentáveis e o estabelecimento de suas metas para a erradicação de problemas sociais e sanitários, sendo a agricultura familiar, considerada uma âncora para o atingimento dessas metas (FAO, 2017).

A América Latina e o Caribe, conta com experiências exitosas na discussão sobre políticas de segurança alimentar e nutricional, e o crescimento do setor agrícola subsidiado por estas discussões, tem aumentado a produção alimentar e tem sido uma das responsáveis pela diminuição da pobreza e da desnutrição nas últimas décadas (FAO, 2017a).

Com esta conjuntura, a Organização das Nações Unidas para a Alimentação e Agricultura, está desenvolvendo em parceria com a Comunidade dos Estados Latino-Americanos e Caribenhos - CELAC, um plano para a agricultura familiar e para o desenvolvimento rural, para promoção da melhoria e intensificação da produção sustentável e de maiores oportunidades entre outras ações (CONSEA, 2017).

No entanto, apesar de a agricultura familiar ser considerada pela Organização das Nações Unidas a responsável pela maioria dos alimentos 
que chagam a mesa dos brasileiros (PORTAL BRASIL, 2017), e ter obtido significativos avanços em termos de políticas públicas para seu fortalecimento, ainda enfrenta problemas tais como a baixa geração e distribuição de ocupação e renda; êxodo rural, estimulado por questões econômicas, cujo principal ator é o jovem agricultor que acaba abandonando a propriedade em busca de melhores condições na cidade; baixa competitividade; baixa eficiência dos sistemas produtivos compativeis ambiental e socialmente; perda da diversidade da agricultura familiar e baixos investimentos em pesquisa $(\mathrm{OEI}, 2017)$.

Merino et al. (2016) apontam também que entre os principais desafios para a agricultura familiar, destacam-se principalmente, questões ligadas a comercialização; os efeitos da globalização do setor alimentar; os aspectos ambientais e a baixa renda obtida com a atividade agrícola, entre outros temas.

Para o Greenpeace (2017) a mudança para outra forma de produzir alimentos de maneira ecológica e socialmente justa é urgente e o modelo global de produção precisa ser revisto. Neste cenário contextual, a gestão de design encontra campo para desenvolvimento de sua prática, a fim de identificar potencialidade e oportunidades de melhoria dos territórios rurais. Por meio de processos criativos, focados no usuário, desenhar as soluções necessárias para que a agricultura familiar e seus agentes possam sair fortalecidos e oferecerem ao mercado produtos de qualidade, com um sistema visual e de comunicação amparados técnica e legalmente; estímulo à participação dos agentes produtivos, aprimorando processos de gestão, sinergia e sintonia com as instituições públicas e privadas aumentando e melhorando o protagonismo dos agricultores para valorização da agricultura familiar.

Com esta composição, procura-se neste artigo apresentar um relato da experiência de valorização da agricultura familiar por meio do design na região norte do estado de Santa Catarina desenvolvidos pelo Núcleo de Gestão de Design e Laboratório de Design e Usabilidade - NGD/LDU, da Universidade Federal de Santa Catarina em parceria com a EPAGRI/SC RURAL.

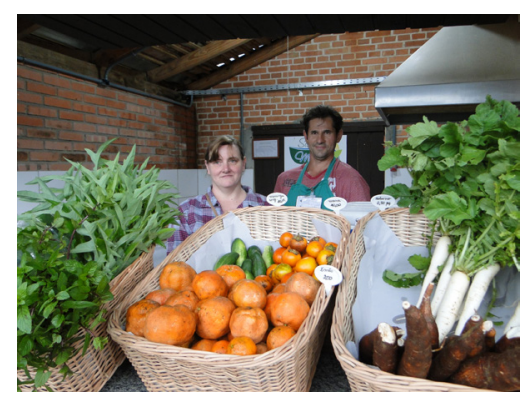

Figura 2: Casal de agricultores - feira de orgânicos - Timbó - SC. Fonte: Acervo NGD, 2016. 


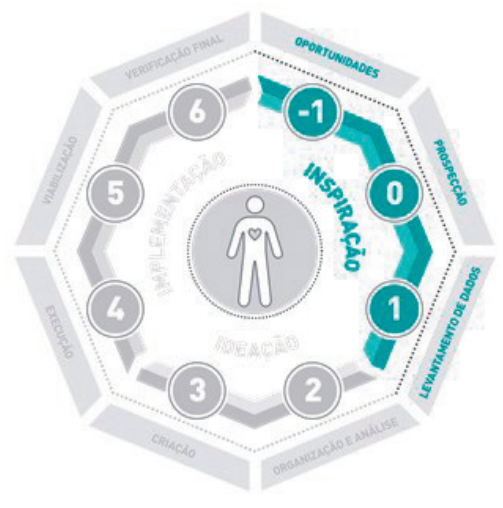

Figura 3: Destaque inspiração.

Fonte: Merino, 2016a, p. 22

\section{METODOLOGIA}

Este artigo se caracteriza como sendo descritivo uma vez que procurou observar, registrar e analisar os dados coletados. Com relação a sua natureza, classifica-se como aplicada. Do ponto de vista da forma de abordagem, classifica-se como qualitativa com procedimento técnico orientado por meio da pesquisa bibliográfica e documental, em um estudo multicaso na região norte do Estado de Santa Catarina (SILVA e MENEZES, 2005; PRODANOV e FREITAS, 2013; LAKATOS e MARCONI, 2010; TRIGUEIRO et al., 2014).

Com relação aos procedimentos metodológicos utilizou-se o guia de orientação para o desenvolvimento de projetos. O GODP é uma metodologia configurada em oito etapas que se fundamentam na coleta de informações, o desenvolvimento criativo, a execução projetual, a viabilização, cujo principal objetivo é fornecer uma sequência de ações que permitam com que o design seja concebido de forma consciente, levando em consideração o maior número de aspectos (MERINO, 2016a). A Figura 3 apresenta a metodologia, com destaque para o momento de inspiração e em razão do andamento do projeto, só serão descritos aqui, as etapas até o presente momento, desenvolvidas.

O momento inspiração é o primeiro da metodologia do guia de orientação para desenvolvimento de projetos e é constituído de três etapas: Oportunidades (-1), Prospecção (0) e Levantamento de Dados (1).

Na etapa Oportunidades ( -1$)$ foram mantidos os primeiros contatos. De acordo com a Figura 2, eles ocorreram em 2014, identificando as principais linhas de ação e possibilidades do Núcleo. Na etapa Prospecção (0), após a verificação das oportunidades foram identificadas e definidas as demandas que nortearam o projeto, e na etapa Levantamento de dados (1), foram realizadas as reuniões e prospecção de dados com a visitação in loco nas 26 propriedades definidas na fase de oportunidades, a fim de se elaborar um perfil dos produtores e do mercado. As visitas às propriedades foram realizadas em parceria com os técnicos da EPAGRI, momento em que era preenchida uma ficha para registro dos dados levantando 
as características do empreendimento, seus integrantes, com a utilização de instrumentação técnica por meio do dinamômetro e termógrafo digital bem como das particularidades dos produtos e serviços. Além disso, registros fotográficos e videográficos foram efetuados (MERINO, 2016a).

As três etapas, oportunidades (-1), prospecção (0) e levantamento de dados (1), compreendem um momento para que a equipe possa entender os atores, o contexto e o produto alvo de análise. Ela parte da observação concreta para o abstrato para mais tarde retornar ao concreto (MERINO, 2016a).

\section{DESENVOLVIMENTO E RESULTADOS}

Um dos maiores desafios das nações e, sobretudo das administrações públicas é garantir a produção de alimentos no campo para suprir as necessidades humanas. O Brasil, a partir deste panorama vem intensificando através de políticas públicas o estímulo à agricultura familiar através da diversificação de linhas de crédito e que levem a variação produtiva nas unidades familiares, uma vez que $84,4 \%$ dos estabelecimentos agropecuários do país são classificados como sendo de agricultura familiar (ALMEIDA, 2016).

A variação produtiva ou diversificação de renda passa a ser, uma estratégia para lidar com os riscos da produção agropecuária que para os casos dos pequenos agricultores, é ainda mais alta, uma vez que todo o capital está investido na sua produção, existindo pouca margem para resistir a estas variações (IPEA, 2016).

Argumenta-se neste cenário que o ótimo design ajuda a criar produtos e serviços mais esteticamente agradáveis em um mundo que muda rapidamente. Ao empregar a prática do design com criatividade e racionalidade, se é capaz de reformular os problemas de forma a criar soluções inovadoras (DMI, 2017).

A influência da inovação nesta esteira perpassa pelos fatores técnicos, humanos, sociais e organizacionais. Para Fernandez (2016) as dimensões que influenciam a inovação são orientação estratégica,

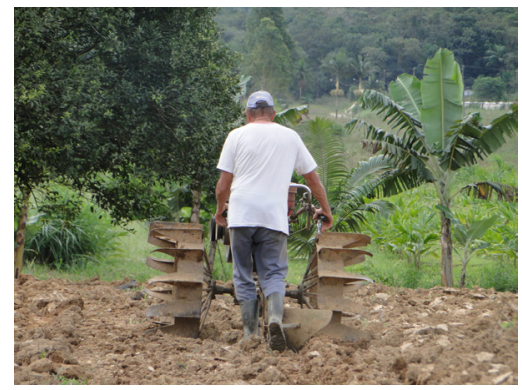

Figura 4: Preparando a terra propriedade rural -SC. Acervo NGD, 2016. 


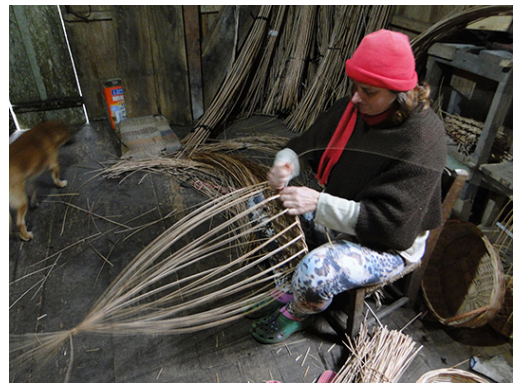

Figura 5: Agricultora produzindo artesanato em vime - Timbó - SC. Fonte: Acervo NGD, 2016. estrutura financeira, a intensidade inovadora do setor, os ciclos de vida tecno-econômicos, o tamanho, a cultura, as formas de colaboração e cooperação assim como o grau de diversificação tecnológica.

Neste sentido, trazendo a ideia de que a experiência é à base da interação com o meio, conceito que vem ganhando espaço em diversas áreas, inclusive o design (GASPARETO, et al., 2016), o desenvolvimento de soluções inovadoras por meio da experiência da valorização da agricultura familiar, permite um processo de modernização da agricultura e de diversificação do sistema produtivo, que atualmente representa, no Brasil, $40 \%$ dos estabelecimentos da agricultura familiar (IPEA, 2016).

Contextualizando as contribuições do design no processo de valorização da agricultura familiar como um desafio dinâmico para o desenvolvimento do Brasil rural e para a superação dos problemas já apontados neste estudo, será apresentado o relato das intervenções do Núcleo de Gestão de Design, na agricultura familiar, por meio do projeto de gestão de empreendimentos rurais e pesqueiros, nas microrregiões de Blumenau e Joinville.

O projeto iniciou em 2014 por iniciativa da Empresa de Pesquisa Agropecuária e Extensão Rural de Santa Catarina-EPAGRI e foi pensado em decorrência da baixa competitividade dos empreendimentos bem como pela falta de organização considerada como fator impactante frente ao mercado consumidor (EPAGRI, 2014). Ainda no ano de 2014 o Núcleo de Gestão de Design e Laboratório de Design e Usabilidade - NGD/LDU, da Universidade Federal de Santa Catarina é convidado a integrar o projeto e em agosto do mesmo ano, inicia sua participação realizando uma reunião com os agricultores familiares, na cidade de Joinville, SC.

Em 2015 deu-se início a segunda fase do projeto com a visita as propriedades que permitiram caracterizar o perfil dos produtores, do produto e do sistema de produção, assim como levantar hábitos cotidianos e informações de mercado. A Figura 6 ilustra a linha de tempo no desenvolvimento do projeto. 


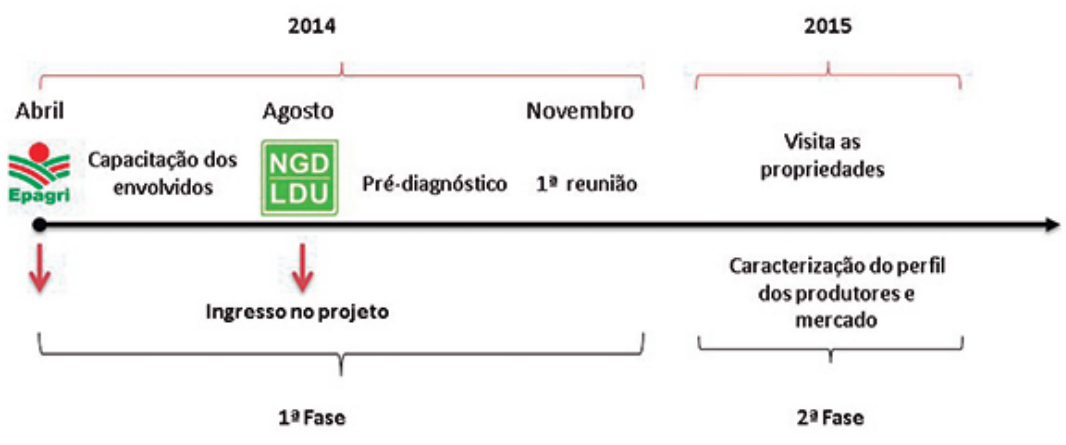

Figura 6: Linha de tempo do desenvolvimento do projeto. Fonte: Autores, 2016.

Foram visitadas 12 propriedades rurais e pesqueiras na microrregião de Joinville. Localiza-se em uma área de 4.670 km², com limites entre as microrregiões de São Bento do Sul, Blumenau, Itajaí, com o Estado do Paraná e com o oceano atlântico, sendo composta por dez municípios (SANTA CATARINA, 1991). A Figura 7 apresenta esquematicamente a localização dos empreendimentos familiares rurais e pesqueiros objeto de estudo.

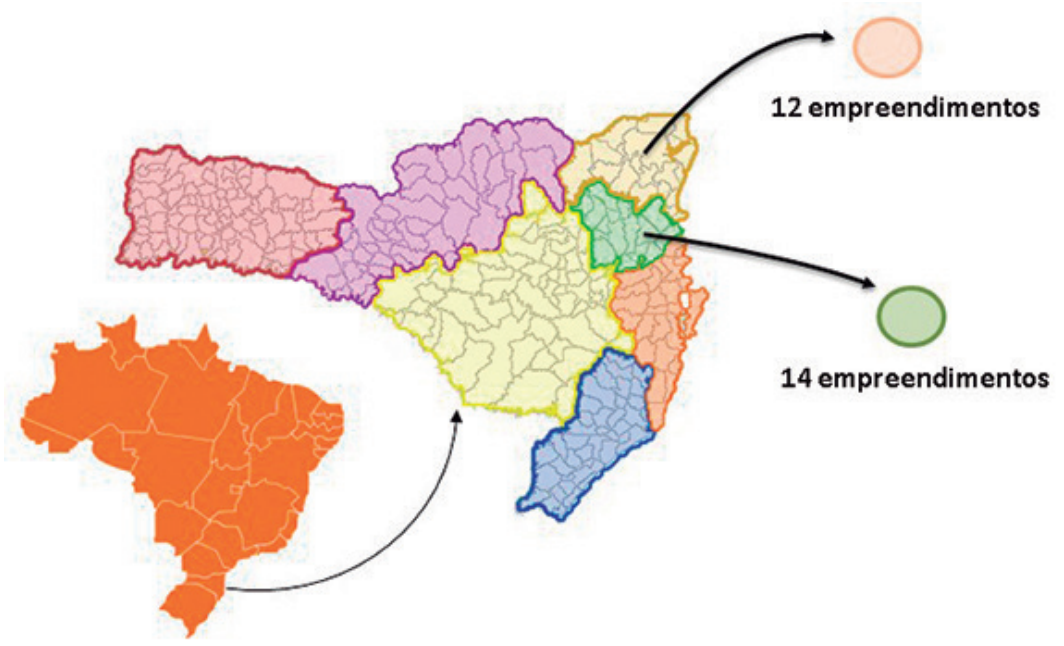

Figura 7: Mapa de localização dos empreendimentos familiares. Fonte: Autores, 2016.

Na microrregião geográfica de Blumenau foram visitados mais 14 empreendimentos. A microrregião localiza-se em uma área de 6.607 km² limitando-se com as microrregiões Joinville, Tijucas, Ituporanga, Rio do Sul, São Bento do Sul e Canoinhas. Compõem esta microrregião, quinze municípios (SANTA CATARINA, 1991).

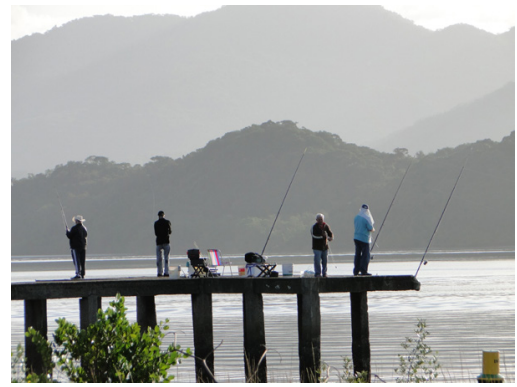

Figura 8: Ambiente para pescaria - São Francisco do Sul - SC. Fonte: Acervo NGD, 2016. 
Figura 8: Base taxonômica. Fonte: Merino, Zacchi, Merino, Alves e Benvenutti, 2016, p. 142.
No total, foram visitadas 26 propriedades localizadas nas duas regiões apresentadas na Figura 6. Na visitação in loco, foram realizadas entrevistas com os agricultores o que possibilitou elaborar um diagnóstico identificando as potencialidades e oportunidades de melhoria de cada propriedade, bem como o levantamento da força palmar e temperatura superficial das mãos com a finalidade de identificar possíveis problemas de saúde, dentre eles artrites reumatoides, mutilações, dentre outras que podem afetar de forma direta o desempenho das atividades.

Foi possivel elaborar uma proposta de base taxonômica, Figura 8 e os resultados mostraram que entre as propriedades identificadas, a produção diversificada corresponde à maioria dos casos.

Em 57,69\% das propriedades identificadas a produção é diversificada nas categorias fruticultura, olericultura, aquicultura e pesca, pecuária e avicultura. Em 42,30\%, ou seja, 11 propriedades observou-se a especialização em um ou mais produtos, destacando-se o cultivo de flores, a produção de produtos derivados do leite, a produção de conservas, produtos panificados, criação de peixes e a produção de acessórios de couro de peixe e também de artesanato, a partir de escamas de peixe.

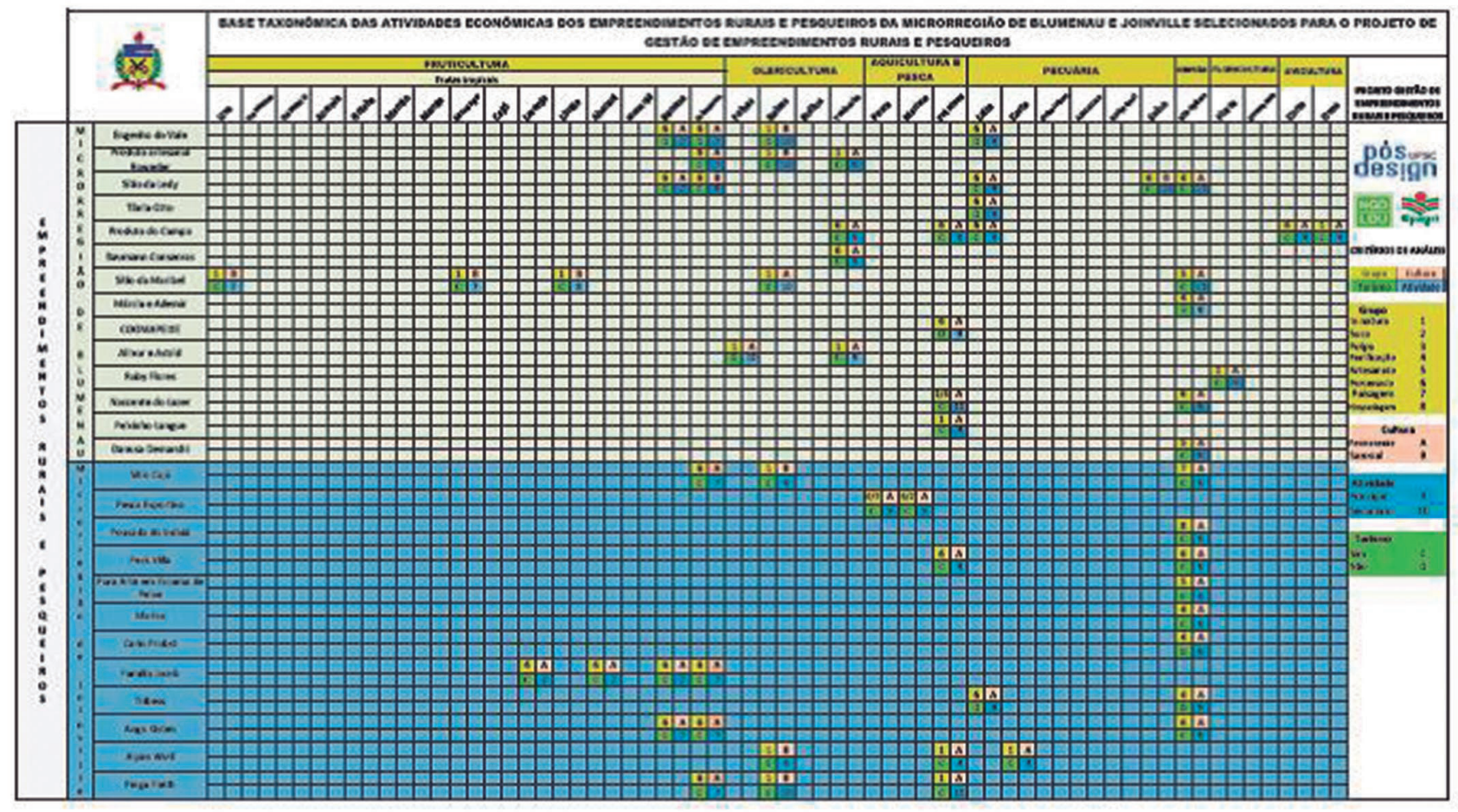


Os resultados apontam também que $26,92 \%$ das propriedades pesquisadas, os agricultores preferem a produção, por meio do processo de processamento de produtos da fruticultura tendo a banana e a cana de açúcar destaque neste contexto. 38,46\% da amostra comercializam sua produção in natura, entre elas uva, morango e limão, raízes e tubérculos, folhas e psicultura.

Considerando o tipo de cultura produzida, procura-se com o Quadro 1, apresentar sinteticamente o tipo de cultura que predomina nas propriedades investigadas nas duas microrregiões.

A fim de mensurar essa intensidade decidiu-se somente assinalar se a cultura é mais ou menos intensa na propriedade estabelecendo +i para as culturas mais intensas e -i para as menos intensas.

Quadro 1 - Predomínio de cultura

\begin{tabular}{|lcc|}
\hline \multirow{2}{*}{ CULTURA } & \multicolumn{2}{c|}{ INTENSIDADE } \\
\cline { 2 - 3 } & JOINVILLE & BLUMENAU \\
\hline Fruticultura & $-\mathrm{i}$ & $+\mathrm{i}$ \\
\hline Olericultura & $-\mathrm{i}$ & $+\mathrm{i}$ \\
\hline Aquicultura e pesca & $+\mathrm{i}$ & $-\mathrm{i}$ \\
\hline Pecuária & $-\mathrm{i}$ & $+\mathrm{i}$ \\
\hline Avicultura & $+\mathrm{i}$ & $-\mathrm{i}$ \\
\hline Atividades pluriativas & $+\mathrm{i}$ & $-\mathrm{i}$ \\
\hline Floricultura & $-\mathrm{i}$ & $+\mathrm{i}$ \\
\hline
\end{tabular}

Fonte: Autores, 2016.

A ideia do Quadro 1 é apresentar o tipo de cultura que predomina nas propriedades. Ou seja, trata-se de um resumo da produção cultivada na propriedade. Enquanto a fruticultura torna-se uma cultura permanente e dividindo-se como atividade principal e secundária para cinco propriedades rurais na região de Blumenau, na região de Joinville, as quatro propriedades que também desenvolvem a fruticultura, a

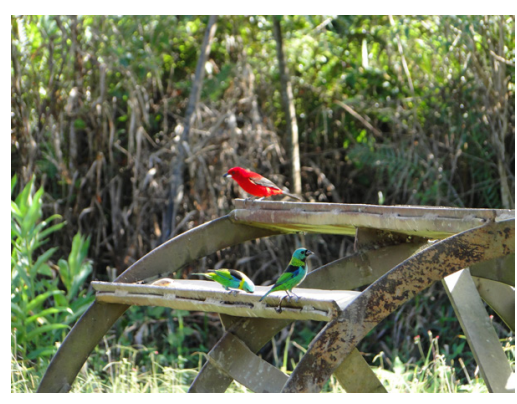

Figura 9: Observação de pássaros propriedade rural - SC. Fonte: Acervo NGD, 2016. 


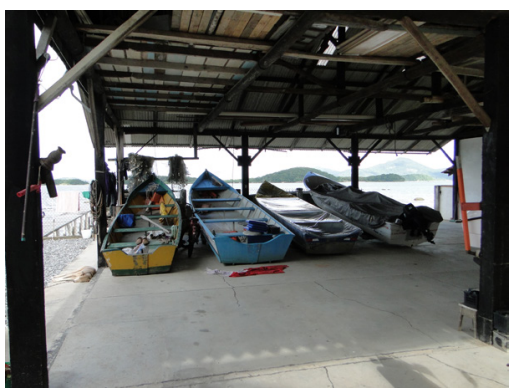

Figura 10: Pesca esportiva - litoral norte de SC. Fonte: Acervo NGD, 2016. consideram como uma atividade principal e cultura permanente. A olericultura está mais presente nas propriedades da microrregião de Blumenau em detrimento das de Joinville. Já a pecuária de corte e produção de leite é mais forte na microrregião de Blumenau. Assim a microrregião de Joinville mostra-se mais intensa na aquicultura e pesca, avicultura e atividades pluriativas ao passo que a microrregião de Blumenau mostrou-se mais intensa na fruticultura, olericultura, pecuária e floricultura.

Com relação ao desenvolvimento do turismo, $84,62 \%$ dos empreendimentos demonstram interesse em explorar o turismo organizado sendo que algumas propriedades já oferecem serviços aos visitantes, destacando-se a hospedagem e a pesca esportiva. Constatou-se neste segmento que a paisagem, estruturas artificiais e hábitos comportamentais contribuem como fonte de oportunidades para a exploração do turismo rural.

Destaca-se que a associação do turismo com o design e os produtos e serviços inerentes da agricultura familiar implica na valorização da agricultura familiar, de seus agentes e dos produtos resultantes.

Esta reputação fica associada ao território que passa a promover um conjunto de valores agregados tais como atividades ecoturísticas, recreação, observação e contemplação da paisagem e de pássaros, criação e manejo de animais, arquitetura típica, sistemas agroecológicos, compras, cachoeiras e rios, componentes existentes nas propriedades tanto na microrregião de Blumenau quanto nas de Joinville, que se tornam ofertas de mercado mediadas pelo design; perspectivas que redinamizam o espaço rural.

Neste contexto além da valorização da agricultura familiar no conjunto, o segmento contribui também para a preservação ambiental e cultural, para a melhoria da prática da manipulação de alimentos e para a valorização do agricultor que reconhecendo sua importância permanece no campo. O caminho do vinho, em São José dos Pinhais, no Paraná, torna-se um bom exemplo. É composto por nove vinícolas, quatro cafés coloniais, nove restaurantes e doze chácaras de lazer e eventos. Ao percorrê-lo, o usuário tem contato com a história local e a riqueza cultural. Além disso, passa a conhecer o processo produtivo do vinho, o que gera mais credibilidade ao produto, a marca e a região (MTUR, 2017). 
Guimarães e Lucca (2014) apontam, que o design orientado para a valorização estabelece ao designer a função de mediador que auxilia a definição de formas de planejamento, produção e comercialização que atenda às necessidades do produtor e do consumidor. Portanto todas as informações coletadas estão sendo tratadas e examinadas para dar continuidade ao projeto de forma cíclica tal como confere a Figura 1 , que destaca somente o momento de inspiração, a fim de propor as necessárias soluções para os agricultores em ação futura.

\section{CONCLUSÃO}

O estudo possibilitou por meio da metodologia GODP, identificar as potencialidades e oportunidades de melhoria nas propriedades integrantes do projeto, por meio do levantamento das demandas e problemática central, recorrendo a coletas de dados em diferentes fontes, realizando visitas em campo, entrevistas e registro fotográfico.

O estudo mostrou ainda que as propriedades nas duas microrregiões de Blumenau e Joinville apresentam uma produção classificada como diversificada, muito embora haja especialização e uma tendência à completa diversificação em todas as propriedades.

Com relação ao desenvolvimento da atividade turística, $84,62 \%$ das propriedades investigadas tem interesse em alavancar a propriedade também por meio da atividade do turismo organizado, explorando os recursos paisagísticos, físicos e infraestruturais da propriedade.

O estudo ainda revelou oportunidades para a prática do design para propor soluções competitivas e sustentáveis para o negócio com vistas a melhorar e valorizar o protagonismo da agricultura familiar no cenário nacional e local, destacando-se projetos na área de diferenciação e diversificação do produto, comunicação, embalagens para armazenagem e transporte, displays, estruturas de sinalização, projeto de identidade visual, organização do ponto de venda, tais como layout, organização das bancadas e tabuleiros, projetos de reuso e descarte, cartões de visita, papelaria interna, folders, banners e cartazes, assim como métodos de gestão do negócio. 
Diante dos fatos relatados até o presente momento, a abordagem do design nos casos estudados pode orientar a valorização da agricultura familiar e melhorar o desempenho do desenvolvimento local por meio da ampliação dos vínculos entre os agentes envolvidos direta e indiretamente.

\title{
5 AGRADECIMENTOS
}

Os autores agradecem a CAPES, ao CNPq, a FAPEU, a EPAGRI/GOVERNO DO ESTADO DE SANTA CATARINA e ao NGD/LDU que viabilizaram esta pesquisa.

\section{REFERÊNCIAS}

\author{
ALMEIDA, Regis Rodrigues de. Agricultura familiar. 2016. Disponivel em: <http:/l \\ mundoeducacao.bol.uol.com.br/geografia/agricultura-familiar.htm>. Acesso em: 18 de agosto \\ de 2016
}

CONDRAF. Conselho Nacional de Desenvolvimento Rural Sustentável. Política de desenvolvimento do Brasil rural. Ministério do Desenvolvimento Agrário. Brasilia. Disponível em http:/www.mda.gov.br/sitemda/secretaria/condraf/apresenta\%C3\%A7\%C3\%A30. Acesso em 08 de fevereiro de 2017.

CONSEA. Conselho Nacional de Segurança Alimentar e Nutricional. América Latina e Caribe pode ser $1^{\text {a }}$ região do mundo a erradicar a fome, diz FAO. Governo do Brasil. Presidência da República: Brasilia, 2017. Disponível em http://www4.planalto.gov.br/consea/. Acesso em 09 de fevereiro de 2017.

DMI. Design Management Institute. Design conscious. Disponivel em http://www.dmi.org/dmi/ html/index.htm. Acesso em 13 de fevereiro de 2017

EPAGRI. Empresa de Pesquisa Agropecuária e Extensão Rural de Santa Catarina. Gestão dos empreendimentos rurais e pesqueiros do litoral norte catarinense visando o desenvolvimento territorial sustentável com identidade cultural. Florianópolis: EPAGRI, 2014

FAO. Food and Agriculture Organization of the United Nations. Panorama de la seguridad alimentaria y nutricional: sistemas alimentarios sostenibles para poner fin al hambre y la malnutrición. FAO: Santiago, 2017. Disponivel em http://www.fao.org/3/a-i6747s.pdf. Acesso em 08 de fevereiro de 2017.

FAO. Food and Agriculture Organization of the United Nations. Retos y perspectivas para la seguridad alimentaria y nutricional en América Latina y el Caribe: de los objetivos de desarrollo del milenio a los objetivos de desarrollo sostenible. FAO: México, 2016. Disponível em http://www. fao.org/about/meetings/regional-conferences/larc34/documents/es/. Acesso 8 de fevereiro de $2017 a$.

FERNÁNDEZ, Mariano Garcia. Influencia de la gestión de la calidad en los resultados de innovación a través de la gestión del conocimiento: un estudio de casos. Innovar, 26(61), 45-64. doi: 10.15446/innovar.v26n61.57119, 2016.

GREENPEACE. Agricultura e alimentação: o futuro em nosso prato. Disponível em http://www. greenpeace.org. Acesso em 10 de fevereiro de 2017. 
GASPARETTO Débora Aita, PEDROZO Danielle Difante, OLIVEIRA Fernanda. Design Conectado: por um mundo de experiências. In: Estudos em Design. Revista (online). Rio de Janeiro: v. 24 n. 2 [2016], p. 112-131. ISSN 1983-196X

GUIMARÃES, Márcio James Soares; LUCCA, André de Souza. Valorização do território: uma via para o design sustentável no Maranhão. In: $11^{\circ}$ Congresso Brasileiro de Pesquisa e Desenvolvimento em Design. Gramado-RS, novembro de 2014.

IPEA. Instituto de Pesquisa Econômica e Aplicada. Diversidade da produção nos estabelecimentos da agricultura familiar no Brasil: uma análise econométrica baseada no cadastro da declaração de aptidão ao PRONAF (DAP). Brasilia: Rio de Janeiro, Ipea, 2016.

LAKATOS, Eva Maria, MARCONI, Marina de Andrade. Metodologia cientifica. São Paulo: Atlas, 2010.

MDA. Ministério do Desenvolvimento Agrário. Plano Safra da agricultura familiar 2016-2017: alimentos saudáveis para o campo e para a cidade. Ministério do Desenvolvimento Agrário. Brasilia. Disponivel em http://www.mda.gov.br. Acesso em 8 de fevereiro de 2017.

MERINO, Giselle Schmidt Alves Díaz, et al. Design e agricultura familiar: ações de valorização e identificação em Santa Catarina. In: $12^{\circ}$ Congresso Brasileiro de Pesquisa e Desenvolvimento em Design. Belo Horizonte, 2016, p. 1659-1670.

MERINO, Giselle Schmidt Alves Díaz. GODP - Guia de Orientação para Desenvolvimento de Projetos: Uma metodologia de Design Centrado no Usuário. Forianópolis: Ngd/ Ufsc, 2016. Disponivel em: «www.ngd.ufsc.brr. Acesso em: 12 jul. 2016a.

MERINO, Giselle Schimidt, ZACCHI, Giancarlo Philippi, MERINO, Eugenio, ALVEZ, Adriana Tomazi BENEVENUTTI, Dione Nery Cavalcanti. A gestão de design na perspectiva da produção de ativos intangíveis na agricultura familiar: um estudo multicaso em Joinville e Blumenau no estado de Santa Catarina. In: $6^{\text {th }}$ IFDP - Systems \& Design: Beyond Processes and Thinking. Valência, Espanha: Univertitat Politècnica de València, 2016, p. 138-147.

MTUR. Ministério do Turismo. Turismo celebra o dia nacional do enólogo: o processo de produção do vinho e a degustação da bebida impulsionam roteiros turísticos pelo Brasil. Ministério do Turismo: Brasilia, 2017. Disponivel em www.turismo.gov.br. Acesso em 23 de fevereiro de 2017

OEl. Organização dos Estados Ibero-americanos. Os desafios da agricultura familiar. Disponivel em http://www.oei.es/historico/divulgacioncientifica/noticias_179.htm. Acesso em 9 de fevereiro de 2017

PORTAL BRASIL. ONU reforça a importância da agricultura familiar. Brasilia 22 de outubro de 2014. Disponivel em http://www.brasil.gov.br/economia-e-emprego. Acesso em 9 de fevereiro de 2017.

PRODANOVE, Cleber Cristiano; FREITAS, Ernani César de. Metodologia do trabalho científico: métodos e técnicas da pesquisa e do trabalho acadêmico. Novo Hamburgo: Feevale, 2013.

SANTA CATARINA. Secretaria de Estado de Coordenação Geral e Planejamento. Subsecretaria de Estudos Geográficos e Estatísticos. Atlas escolar de Santa Catarina. Rio de Janeiro: Aerofoto Cruzeiro, 1991. Disponivel em http://www.spg.sc.gov.br/mapas/atlas/atlas.html. Acesso em 08 de março de 2017.

SILVA, Edna Lúcia da; MENEZES, Estera Muszkat. Metodologia da pesquisa e elaboração de dissertação. Florianópolis: UFSC, 2005

TRIGUEIRO, Rodrigo de Menezes, et al. Metodologia científica. Londrina: Editora e Distribuidora Educacional, 2014. 
